\title{
The Way the Wind Blows Matters to Ecosystem Water Use
}

\section{Efficiency}

\section{Nicola Montaldo ${ }^{1}$, and Ram Oren ${ }^{2}$}

1- Dipartimento di Ingegneria civile, ambientale e architettura, Università di Cagliari, ITALY

[nmontaldo@unica.it]

2- Nicholas School of the Environment, Duke University, Durham, NC, USA, and Department of Forest Ecology \& Management, Swedish University of Agricultural Sciences (SLU), Umeå, Sweden [ramoren@duke.edu]

\author{
Revised for publication in \\ Agricultural and Forest Meteorology
}

September 2015

\section{Corresponding Author:}

Nicola Montaldo

Dipartimento di Ingegneria civile, ambientale e architettura, Università di Cagliari

Via Marengo, 3, I-09123 Cagliari (ITALY)

+39.070.6755301 (Phone); +39.070.6755310 (Fax); nmontaldo@unica.it 


\section{Abstract}

In many regions, atmospheric conditions change frequently with shifts of wind direction, extending maritime influences far inland or continental influences to coastal ecosystems. Climate models predict changes in both wind direction and velocity; these changes could potentially impact ecosystems mass and energy exchanges with the atmosphere. Using data on climate (wind speed and direction, air temperature and humidity) and ecosystem-scale fluxes (eddy-covariance evapotranspiration and $\mathrm{CO}_{2}$ flux) from the Mediterranean island of Sardinia, we evaluated whether the frequency of certain wind characteristics, potentially affecting ecosystem $\mathrm{CO}_{2}$ uptake, have changed over five decades, and whether these characteristics are indeed linked to ecosystem gas-exchange responses of the studied ecosystem. The analyses shows that days dominated by summer Mistral winds decreased on average $3 \%$ per decade, and that wind direction affects biosphere-atmosphere exchange of carbon but not water. High velocity cool Mistral winds from continental Europe undergo limited thermal equilibration with the land surface after embarking on the land, trebling vapor pressure deficit $(D)$ as they cross the island. In contrast, arriving with a similar $D$, lower velocity, warmer Saharan Sirocco winds heat up, thus increasing $D$ five-fold only $50 \mathrm{~km}$ inland. Over a mixed pasture-woodland (grass-wild olive), while soil moisture was low and constant, daytime net carbon exchange $\left(N E E_{\mathrm{d}}\right)$ averaged 2.3-fold higher $(P<0.001)$ in Mistral than Sirocco days, largely reflecting the theoretically expected response of canopy conductance $\left(g_{\mathrm{c}}\right)$ to variation of $D$. Because the product of $g_{\mathrm{c}}$ and $D$ encodes the key ecosystem compensatory mechanism, the reciprocal $g_{\mathrm{c}}-D$ response maintained similar ecosystem evapotranspiration $\left(E_{\mathrm{e}}\right)$. Thus, summertime ecosystem water-use efficiency $\left(W_{\mathrm{e}}=N E E_{\mathrm{d}} / E_{\mathrm{e}}\right)$, was $\sim 66 \%$ higher during Mistral than other days. The historical decrease of Mistral frequency reduced the estimated summertime $N E E_{\mathrm{d}}>30 \%$. The analyses demonstrate that alteration of dominance of air masses predicted with future climate will amplify or negate the positive effect of increased atmospheric $\left[\mathrm{CO}_{2}\right]$ on $W_{\mathrm{e}}$, and should be considered when assessing climate change impact on $N E E$. 
key words: water use efficiency, wind impact, terrestrial ecosystem, climate change, carbon assimilation, canopy conductance, transpiration, wild-olive ecosystem

\section{Introduction}

In many locations, changes in weather conditions reflect interacting moist maritime and dryer continental air masses (Fosberger and Schroeder, 1966; Conil and Hall, 2006; Hughes and Hall, 2010). Attention is typically focused on the capacity of strong winds to fan regional fires, threatening human habitation and natural habitats, and reducing carbon (C) storage, net ecosystem $\mathrm{CO}_{2}$ exchange (NEE) and latent heat flux. However, depending on their origin, winds can bring dry continental air to the coast [e.g., Santa Ana winds along the southern California coast (Conil and Hall, 2006; Hughes and Hall, 2010)] or cool maritime air far inland (Venkatram, 1977; Stunder and Sethuraman, 1984; Garratt, 1985; Furberg et al., 2002). In these regions, water and carbon fluxes may respond to meso- and macroscale weather patterns (Haxeltine and Prentice, 1996; Schimel et al., 2001; Montaldo et al., 2013), yet the effects of wind direction have been explicitly considered only in footprint analyses, focusing mostly on $<1 \mathrm{~km}$ around instrumented towers, and on the relationship between the characteristics of the contributing source/sink area and measured fluxes (Schmid, 2002; Detto et al., 2006, Oren et al., 2006). Thus, no explicit assessment has been made of the effects of coarse-scale weather phenomena and wind characteristics on biosphere-atmosphere exchanges of mass and energy.

Recent analysis of the positive effects of rising atmospheric $\left[\mathrm{CO}_{2}\right]$ on ecosystem-scale wateruse efficiency ( $W_{\mathrm{e}}$, the amount of carbon captured by the ecosystem per unit of water it uses) excluded Mediterranean ecosystems because long-term $\left[\mathrm{CO}_{2}\right]$ effects in these ecosystems are difficult to isolate from the effects of summer droughts (Keenan et al., 2013). However, the summer-dry nature of 
Mediterranean climate provides a background of stable soil moisture, uniquely suitable for assessing the effect of wind characteristics on $W_{\mathrm{e}}$.

Popular awareness in many locations around the globe associates atmospheric conditions with the direction from which the winds arrive. In the western Mediterranean island of Sardinia, fast moving French Mistral winds bring relief from the summer heat (although can fan fires) as they travel on land, while slower Saharan Sirocco winds bring oppressive heat (Fig. 1, Lionello and Sanna, 2005; Burlando 2009). As the weather changes with wind direction, decreasing stomatal conductance with increasing vapor pressure deficit $(D)$ (above a threshold of usually 0.5-1 kPa, e.g., Duursma et al., 2008) may keep transpiration, the dominant component of evapotranspiration, relatively constant (Oren et al., 1999), if the canopy is well-coupled to the atmosphere (Kim et al., 2013). However, decreased stomatal conductance is likely to restrict $\mathrm{CO}_{2}$ uptake, thus reducing $W_{\mathrm{e}}$. Indeed, a decrease of $W_{\mathrm{e}}$ with increasing $D$ is well-documented (Meinzer, 1982; Baldocchi et al., 1987; Berbigier et al., 2001), but the potential impact of such effect on $N E E$ in the context of changing wind characteristics with climate is yet to be quantified.

The frequency of winds from different directions in the western Mediterranean summer are expected to change in frequency and extent with climate change (McInnes et al., 2011; Rasmussen et al., 2011). For example, models predict decreasing mean wind speed and summer Mistral frequency in southern France over the coming four decades (Najac et al., 2009; Najac et al., 2011). We obtained and analyzed historical wind data (five decades) for Sardinia in the Mediterranean basin, a key area for investigating global change impacts owing to its transitional climate and the high spatiotemporal variability of ecosystem function and biodiversity (Doblas-Miranda et al., 2015). We tested the hypothesis that (H1) the frequency of Mistral has already began to decrease over the record period. Using output from MACC II re-analysis (Inness et al., 2013) available at the ECMWF (European Centre for Medium-Range Weather Forecasts), we focused primarily on Mistral and Sirocco winds 
embarking Sardinia evaluating the hypothesis that (H2) the high velocity Mistral winds are of lower $D$ than the lower velocity Sirocco.

Air temperature $\left(T_{\mathrm{a}}\right)$ may decrease as the air mass (in the generated internal boundary layer) embarks the coast and travels over land where the elevation increases, and may rise depending on the contact time with the surface and the sensible heat flux from the surface (Venkatram, 1977; Raynor et al., 1979; Stunder and Sethuraman, 1984). We therefore assessed the changes in $D$ due to the net effect of these processes on temperature as Mistral and Sirocco winds of different velocities climb on Sardinia reaching similar elevation near the coast of embarkation. Considering the thermal energy conservation equation integrated from the surface to the height of the entrainment zone $\left(z_{e}\right.$ assumed equal to $800 \mathrm{~m}$ ), the change of $T_{\mathrm{a}}$ over time, $t$, to a reference horizontal distance from the coast, $x$, can be estimated with (Venkatram, 1977; Stunder and Sethuraman, 1984; Plant and Atkinson, 2002; Moene and Van Dam, 2014, Anton Beljaars, personal communication):

$\frac{\partial T_{a}}{\partial t}=u \frac{d T_{a}}{d x}=-\frac{1}{\rho c_{p}} \frac{\partial H}{\partial z}=\frac{H_{s}-H_{e}}{\rho c_{p} z_{e}}$

where $z$ is the vertical axis, $H$ is the sensible heat flux, $H_{s}$ is the sensible heat flux from the surface, $H_{e}$ is the sensible heat flux from the entrainment zone (about $15 \%$ of $H_{s}$, e.g., Huang et al., 2011), $u$ is the wind velocity, $\rho$ is the air density and $c_{p}$ is the specific heat capacity. Accounting in addition for the adiabatic cooling as the air mass climbs the Sardinian mountain range to $600 \mathrm{~m}$ a.s.l., the change of $T_{\mathrm{a}}$ can be estimated in discrete form as:

$\Delta T_{a}=\frac{H_{s}-H_{e}}{\rho c_{p} z_{e}} \frac{\Delta x}{u}-l_{r} z_{m s}$

where $l_{r}$ is the adiabatic lapse rate $(=0.75$ for average air saturation conditions $)$ and $z_{m s}$ is the height a.s.l., $\Delta x$ is the distance between the coast and the reference point. One of the reference points (Orroli micrometeorological station, Fig. 1) was collocated with an eddy-covariance flux site providing measurements of $H_{s}$ for $\Delta T_{\mathrm{a}}$ estimates based on Eqn. 2, as well as estimates of evapotranspiration and 
NEE over four years (2003-2006). Focusing on these years, we hypothesized that (H3) fast Mistral winds will remain cool as they climb the mountain range and cross the island, while the slow Sirocco winds will warm up over a short distance from the coast, thus further increasing in $D$.

During rainless periods in water-limited ecosystems, canopy transpiration is the dominant component of evapotranspiration ( $E_{\mathrm{e}}$, or latent heat flux calculated with eddy covariance instruments) because evaporation from wet surfaces and soil is negligible (Wetzel and Chang, 1987; Granger and Gray, 1989). Thus, $E_{\mathrm{e}}$ as surrogate of canopy transpiration is essentially the product of total canopy conductance, $g_{\mathrm{c}}$, and atmospheric $D$ :

$E_{\mathrm{e}}=g_{\mathrm{c}} D$,

assuming that leaf and air temperature are similar, and aerodynamic conductance is high relative to stomatal conductance (Jones, 1998; Novick et al., 2004), both safe assumptions considering the high u conditions involved (Kim et al., 2013). However, $g_{\mathrm{c}}$ is not independent of $D$, but decreases as the driving force of transpiration increases in a manner consistent with maintaining the hydraulic integrity and functionality of the water conduits of the xylem (Oren et al., 1999), avoiding the development of tension that might result in catastrophic cavitation. One expression of such relation is $g_{\mathrm{c}}=\mathrm{g}_{\mathrm{c}, \mathrm{ref}}-m$ $\ln (D)$, where $\mathrm{g}_{\mathrm{c}, \text { ref }}$ is reference conductance at $D=1 \mathrm{kPa}$, and $m=0.6 \cdot g_{\mathrm{c} \text {,ref }}$ for a large number of species (Oren et al., 1999), similar to predictions from leaf-level stomatal optimization theories (Katul et al., 2009). The stomatal conductance reduction with increasing $D$ can compensate for the increased driving force $(D)$, resulting in $E_{\mathrm{e}}$ remaining relatively invariant over a large portion of the range of $D$ (Katul et al., 2009).

When soil moisture is low, it is also reasonable to assume that decomposition and $\mathrm{CO}_{2}$ efflux from the soil surface are low (Oishi et al., 2013), and the daytime net flux of $\mathrm{CO}_{2}$ across a plane above the canopy, $F_{\mathrm{c}}$, is dominated by net canopy photosynthesis $\left(A_{\mathrm{c}}\right)$. Thus, $F_{\mathrm{c}}$ (expressed positively to 
reflect photosynthesis) as surrogate of $A_{\mathrm{c}}$ can be estimated following Fick's law of diffusion and adjusting $g_{\mathrm{c}}$ for the diffusivity ratio of $\mathrm{CO}_{2} / \mathrm{H}_{2} \mathrm{O}$ (Cowan, 1978):

$F_{c}=\frac{g_{c}}{1.6} c_{a}\left(1-\frac{C_{i}}{C_{a}}\right)$

where $c_{a}$ and $c_{i}$ are the $\mathrm{CO}_{2}$ concentrations in the ambient atmosphere and in the intercellular space in the leaf, respectively. Combining the physiological relation described above, as $D$ increases and $g_{c}$ decreases, $F_{\mathrm{c}}$ should also decrease. Thus, while the offsetting response of stomata to changes in $D$ should render $E_{\mathrm{e}}$ insensitive to wind-induced atmospheric changes, $N E E_{\mathrm{d}}$ (daytime net ecosystem carbon exchange, the sum of daytime $F_{\mathrm{c}}$ ) should benefit from wind conditions that maintain cool air mass inland, but will decrease greatly (i.e. $N E E_{\mathrm{d}}$ approaches zero) when the air heats up. This hypothesis (H4) was tested with eddy covariance data obtained over the four summers at Orroli. Corollary to this hypothesis, $W_{\mathrm{e}}\left(=N E E_{\mathrm{d}} / E_{\mathrm{e}}=c_{\mathrm{a}}\left(1-c_{\mathrm{i}} / c_{\mathrm{a}}\right) / 1.6 D\right.$; based on Eqns 3 and 4 , averaged over daytime) would decrease with $D$ in proportion to the theoretical stomatal response, unless $F_{C}$ is strongly influenced by respiration, $E_{\mathrm{e}}$ is strongly influenced by evaporation, or $c_{\mathrm{i}} / c_{\mathrm{a}}$ compensates somewhat for stomatal closure.

Finally, we estimated the effect of observed inter-annual variation and half-century long trend in annual Mistral-day frequency on summertime $N E E$.

\section{Materials and methods}

\section{Setting}

Sardinia is covered by vegetation typical of the region (Fig. 1), in equilibrium with Mediterranean climate and a long history of anthropogenic influences (Vinelli, 1926). The climate at the flux site is maritime Mediterranean, with a mean annual precipitation (1922-2007) of $643 \mathrm{~mm}$, and mean July 
precipitation of $11 \mathrm{~mm}$. Mean annual $T_{\mathrm{a}}$ is $14.6{ }^{\circ} \mathrm{C}$, with mean July $T_{\mathrm{a}}$ of $23.7{ }^{\circ} \mathrm{C}$. The soil ranges $6-34$ $\mathrm{cm}$ in depth, averaging $13 \pm 5 \mathrm{~cm}$ (SD), thus quickly plunging into water-limited conditions during the rainless summer (Detto et al., 2006; Montaldo et al., 2008). The soil is silt loam (19\% sand, 76\% silt, $5 \%$ clay) with a bulk density of $1.38 \mathrm{~g} / \mathrm{cm}^{3}$ and a porosity of $53 \%$.

During 2003 - 2006, we monitored land surface fluxes of energy, water, and $\mathrm{CO}_{2}$ with eddycovariance instruments (Baldocchi, 2003) mounted on a $10 \mathrm{~m}$ micrometeorological tower over a mixed pasture-wild olive vegetation in the Flumendosa river basin (Fig. 1, 39 41' 12. 57" N, $9^{\circ} 16^{\prime} 30.34^{\prime \prime}$ E, 500 m a. s. 1.; details in Detto et al., 2006; Detto et al., 2008; Montaldo et al., 2008; Montaldo et al., 2013). The landscape is a patchy mixture of tree clumps forming canopy cover over $\sim 35 \%$ of the footprint area, $\sim 1.5 \mathrm{~km}^{2}$ on a gently sloping $\left(\sim 3^{\circ}\right.$ from NW to SE) plateau, while inter-clump zones are covered by herbaceous and grass species during high moisture periods but are largely exposed, dry soil surface during the rainless summer months. The dominating trees species is wild olive (Olea sylvestris) in patches ranging in height 3.5-4.5 m, with scattered 6-7 m emergent individual of cork oak (Quercus suber), and shorter shrubs (Asparagus acutifolius and Rubus ulmifolius); vines (Crataegus azarolus and Smilax aspera) often climb the trees.

\section{Measurements}

Three dimensional wind velocity, temperature and $\mathrm{CO}_{2}$ and water vapor gas concentration time series sampled at $10 \mathrm{~Hz}$ and averaged over 30 minutes intervals were used for estimating $E_{\mathrm{e}}, H$ and $F_{\mathrm{c}}$ based on the standard eddy-covariance method. These were measured with a Campbell Scientific CSAT-3 tri-axial sonic anemometer and a Licor-7500 $\mathrm{CO}_{2} / \mathrm{H}_{2} \mathrm{O}$ infrared gas analyzer positioned adjacent to each other at the top of the $10 \mathrm{~m}$ tower. The effect of the gentle slope of the plateau was removed by utilizing the conventional planar fit method, and the Webb-Pearman-Leuning adjustment was applied (Detto et al., 2006; Detto et al., 2008). 
The Vaisala HMP45 was used to measure $T_{\mathrm{a}}$ and relative humidity $(R H)$. Vapor pressure deficit, $D$ was calculated as $D=e^{*}\left(T_{\mathrm{a}}\right) \cdot(1-R H)$, where the saturation vapor pressure $e^{*}$ is related to $T_{\mathrm{a}}$ through the Clausius-Clayperon equation (Stull, 1988). The changes in $D$ from sea to particular locations on the island was calculated based on changes in both air temperature $\left(\Delta T_{\mathrm{a}}\right)$ and specific humidity $\left(Q_{\mathrm{a}}\right)$ converted to $R H$.

Three infrared transducers, IRTS-P (Apogee Instrument, accuracy of $0.3^{\circ} \mathrm{C}$ ) were used to measure the surface temperature of the different land cover components. The incoming and outgoing shortwave and longwave radiation components were measured by a CNR-1 (Kipp \& Zonen) integral radiometer positioned at $10 \mathrm{~m}$ with a hemispherical field of view.

The two-dimensional footprint model of Detto et al. (2006) was used for interpreting eddycorrelation measurements in the context of the contributing land cover area. For estimating the fraction of vegetation cover distribution of the site, a multispectral high spatial resolution (2.8 m ) Quickbird satellite images (DigitalGlobe Inc.) was acquired (08/03/2003) (Detto et al., 2006). A supervised classification scheme based on the parallelepiped algorithm (Montaldo et al., 2008) allows distinguishing tree from bare soil from the image.

Seven frequency domain reflectometer probes (FDR, Campbell Scientific Model CS-616) were inserted in the soil close to the tower (3.3-5.5 m away) to estimate the mean soil moisture $(\theta)$ within the root-zone. FDR calibration $\left(\theta=2.456-7.135 \tau+6.701 \tau^{2}-1.884 \tau^{3}\right.$, where $\tau$ is the output period in milliseconds) was made using 15 periodic gravimetric water content samples taken over a wide range of $\theta\left(0.08-0.52 \mathrm{~m}^{3} \mathrm{~m}^{-3}\right)$ near the probes.

\section{Criteria for identifying Mistral and Sirocco days}

During 2003-2006 study period, soil moisture of approximately $0.1 \mathrm{~m}^{3} \mathrm{~m}^{-3}$ prevailed from about midJune (DOY 170) through the end of August (DOY 243), or 74 days annually. We considered these 
days over the four study years, excluding rainy days. We used the output from MACC II re-analysis (Inness et al., 2013) available at the ECMWF database producing a grid of $1.125^{\circ}$ of latitude and longitude cells of wind velocity and direction at three-hour intervals, selecting days associated with specific wind conditions generated in the continents to the northwest or the southeast. We analyzed six cells to each direction and additional two cells partially overlaying the island and partially the sea nearby. To identify Mistral conditions, we analyzed the five northwestern, two Sardinian, and one southeastern cells, and for Sirocco conditions the five southeastern cells were substituted with those to the northwest, and the southeastern cell was substituted with a northwestern one (Fig. 1). Mistral winds are typically stronger than Sirocco winds. Thus, Mistral days were those in which, averaged over the four daytime model outputs, wind direction was between $275^{\circ}$ and $335^{\circ}$ and average wind velocity exceeded $7 \mathrm{~m} \mathrm{~s}^{-1}$; in Sirocco days, daytime wind direction averaged over the seven cells was $120^{\circ}-180^{\circ}$, and wind velocity $>5 \mathrm{~m} \mathrm{~s}^{-1}$. These rather conservative criteria selected days in which wind direction was similar over the entire island, and excluded transition days and days in which localize weather produced conditions similar to a Mistral or Sirocco but are not clearly influenced by mesoscale driven maritime intrusion. Data from the single cell closest to the shore from each direction was used to estimate $T_{\mathrm{a}}, Q_{\mathrm{a}}$ and $D$ of the arriving maritime air; during days classified as neither Mistral nor Sirocco, the average of both cells was used.

For the historical analysis of summertime Mistral-day frequency we used long term data from the Alghero meteorological station (Fig. 1). During the period 2003-2006, the wind conditions of the MACC II re-analysis outputs produced wind velocity of 1.47 relative to the attenuated velocity on land as measured at Alghero. Thus, Mistral days were reconstructed historically as these in which the wind is from the northwest and its average velocity is $>4.75 \mathrm{~m} \mathrm{~s}^{-1}$ at Alghero. We also used long term data from the Elmas meteorological station, which is the historical meteorological station of Cagliari and is located on the south of Sardinia (Fig. 1), for analyzing summertime Sirocco-day frequency in contrast 
with the northwestern Alghero Mistral data. During the period 2003-2006, the wind conditions of the MACC II re-analysis outputs produced wind velocity of 0.94 relative to the velocity on land as measured at Elmas. Thus, Sirocco days were reconstructed historically as these in which the wind is from the southeast and its average velocity is $>5.3 \mathrm{~m} \mathrm{~s}^{-1}$ at Elmas.

Assessing the effect of travel over the island on $T_{a}$ and $D$ was based on two sets of meteorological stations: for Mistral wind direction a coastal station (Alghero) and another $50 \mathrm{~km}$ from the coast and 639 m elevation (Macomer), and for Sirocco wind direction a coastal station (Capo San Lorenzo) and another $53 \mathrm{~km}$ from the coast and $625 \mathrm{~m}$ elevation (Orroli). Data of Perdasdefogu meteorological station (which is close to the Orroli station, $7 \mathrm{~km}$ south east) are also considered (Fig. 1).

Lastly, historical monthly series of the North Atlantic Oscillation (NAO; Hurrell, 1995) and of the Mediterranean oscillation index (MOI; Palutikof et al., 1996) have been collected from the Climatic research unit database.

\section{Results}

The historical data from Alghero showed high and somewhat cyclical variance of the proportion of summer days classified as Mistral based on wind speed and direction, but also an overall decrease in the proportion (from $\sim 27 \%$ to $7 \%$ of the summer days, a significant decrease trend, tested using the Mann Kendall test, $\tau=-0.43, p<0.0001$ ) over the five decades (Fig. 2, $0.41 \%$ decrease of Mistral days per year, $p<0.0001)$. The cyclical pattern was not related to the North Atlantic Oscillation $(p=$ $0.58)$, showing only slightly better correlation of $(p=0.23)$ with the Mediterranean Oscillation index, computed as normalized pressure difference between Israel and Gibraltar. However, the proportion of summer days in Mistral conditions was inversely well-correlated with independently measured summer $T_{\mathrm{a}}$ in Alghero $(p=0.0002 ; r=-0.51)$. Over the same period, the historical, five-decade data from 
Elmas-Cagliari showed an increase of the frequency of Sirocco days in summer (from $~ 12 \%$ to $39 \%$ of the summer days, a significant increase trend, tested using the Mann Kendall test, $\tau=0.38, p<0.0001$ ) (Fig. 2, $0.57 \%$ increase of Sirocco days per year, $p<0.0001$ ), highlighting a surprising shift from Mistral to Sirocco conditions.

Daytime average soil moisture at the flux site (Orroli) during the summers of 2003-2006 was mostly below $0.1 \mathrm{~m}^{3} \mathrm{~m}^{-3}$, with rare excursions associated with the unusual summer rains (Fig. 3a). However, the relatively invariant soil moisture was concurrent with high variance of daytime average $D$, ranging five-fold from low to high values (even excluding rain days; Fig. 3b). An example of the initial conditions of embarking Mistral and Sirocco air masses, as well as their change with distance from the coast of embarkation is shown in Fig. 4a. A short distance from the coast, Mistral days were characterized by lower $D$ than Sirocco days. On average, re-analysis data shows that, over the Mediterranean near the coast both $T_{\mathrm{a}}$ and $Q_{\mathrm{a}}$ of Mistral days $(n=28)$ were lower $(p<0.0001)$ than these quantities of Sirocco days $(n=20$; Fig. $4 \mathrm{~b}): T_{\mathrm{a}}$ was 22.9 and $25.7^{\circ} \mathrm{C}$ and $Q_{\mathrm{a}}$ was 12.7 and $16.5 \mathrm{~g}$ $\mathrm{kg}^{-1}$ during Mistral and Sirocco, respectively. Furthermore, moving from the coastal meteorological stations to a similar elevation and distance from the coast, where the next downwind stations are located, the difference between the air masses increased (Fig. 4c): while both $T_{\mathrm{a}}$ and $Q_{\mathrm{a}}$ of Mistral air decreased (both $p<0.0001$, one-sample t-test), $T_{\mathrm{a}}$ of Sirocco air increased $(p=0.002)$ as its $Q_{\mathrm{a}}$ declined slightly $(p=0.005 ; p<0.001$ for differences between Mistral and Sirocco in the behavior of both quantities). The observed $\Delta T_{\mathrm{a}}$ during Mistral and Sirocco days was captured by the simplified calculations (Eqn. 2). The adiabatic cooling is $\sim 4.7^{\circ} \mathrm{C}$ for both wind directions. The measured and calculated $\Delta T_{\mathrm{a}}$ were $-2.60 \pm 1.66{ }^{\circ} \mathrm{C}$ and $-1.59 \pm 0.67{ }^{\circ} \mathrm{C}$ (mean and SD) for Mistral, and $2.38 \pm 2.83{ }^{\circ} \mathrm{C}$ and $2.25 \pm 1.14^{\circ} \mathrm{C}$ for Sirocco. As expected based on Eqn. (2), the actual $\Delta T_{\mathrm{a}}$ was inversely related to $u\left(r^{2}=0.44, p=0.001\right)$, likely reflecting the contact time with the underlying surface. 
We assessed the effects on $D$ of differences in $T_{\mathrm{a}}$ and $Q_{\mathrm{a}}$ associated with Mistral, Sirocco (Fig. 4b) and days classified as influenced by local weather, and the changes in these quantities following embarkation on land (Fig. 4c). Over the sea near the coast, the air mass influenced by neither Mistral nor Sirocco winds had a $\sim 0.2 \mathrm{kPa}$ greater $D$ than under more windy conditions, probably reflecting incursion of dryer air mass from the island (Fig. 5; one-way ANOVA $p<0.001$; Dunn test for mean separation, $p<0.05$ ), but by the time the three air masses arrived at the flux site (Orroli) the pattern of difference changed $(p<0.001)$. As shown in the example (Fig. 4a) most of the change occurred within $\sim 50 \mathrm{~km}$ from the coast, and the difference observed at Orroli (Fig. 5) is attributed to a smaller rise in $D$ for the fast Mistral winds as compared to Sirocco or more locally influenced slower winds.

The footprint analysis showed that fluxes during Mistral days were somewhat less dominated by tree cover (32\%) than during Sirocco days (45\%) (see Fig. 3.a of Detto et al., 2006). Given the dry soil between tree patches, daily $E_{\mathrm{e}}$ was unrelated to $D$ during the period of $\theta \sim 0.1 \mathrm{~m}^{3} \mathrm{~m}^{-3}$ ( $p=0.20$; Fig. 6a), while higher $N E E_{\mathrm{d}}$ values corresponded to days of low $D$, which tend to be Mistral days $(p=$ 0.001 ; Fig. 6b). The insensitivity of $E_{\mathrm{e}}$ to $D$ over a large portion of the $D$ range is a reflection of the inverse relation observed between daytime average $g_{\mathrm{c}}$ and $D$ (Fig. 6c), which had a similar slope to the theoretical (0.6). Therefore, as $D$ increased and $g_{c}$ decreased keeping the transpiration rate in check, $N E E_{d}$ decreased. Note that (1) $\left(1-c_{\mathrm{i}} / c_{\mathrm{a}}\right)$, calculated based on equations 3 and 4 , was unrelated to $D(p=$ $0.25)$, (2) nighttime $F_{\mathrm{c}}$ was weakly correlated to temperature $\left(\mathrm{r}^{2}=0.05 ; p<0.001\right)$ suggesting that the variation in the rather high nighttime temperatures did not influence respiration activity (e.g., Tagesson

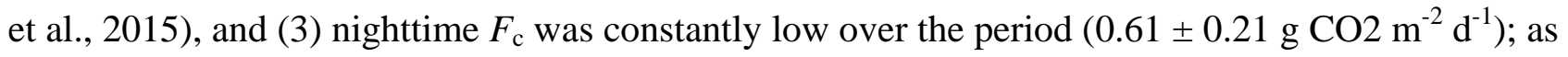
assumed, this makes the decrease of $N E E_{d}$ related only to the decrease of $g_{c}$. Because $W_{\mathrm{e}}$ is also inversely related to $D$, it decreased with increasing $D$ in a similar way to $g_{c}$ (Fig. 6c); the normalized quantities decreased with $D$ similarly $(p=0.84)$. Of 296 days of daily flux data corresponding to $\theta \leq$ $0.1 \mathrm{~m}^{3} \mathrm{~m}^{-3}$, days classified as Mistral showed higher $g_{\mathrm{c}}$ and $W_{\mathrm{e}}$ than days unaffected by either 
mesoscale phenomena ( $p<0.001$ for both), while the fewer Sirocco days showed higher variation and less obvious effects (Fig. 6d).

The five-decade long decreasing trend of Mistral reflects a change from an average of 16 dryseason days in 1966 to an average of 4 days in to 2013, however the cyclical temperature reflects interannual variation from 19 to 3 days, relative to 7 days in the 2003-2006 investigation period (Fig. 2). We investigate the impact of the long-term decline and inter-annual variation of Mistral days on $N E E_{\mathrm{d}}$ using Eqn. (4). To estimate $g_{c}$ we used a simplified form of the Jarvis type formulation (Jarvis, 1976) as the intensity of incoming radiation was not limiting and thus did not affect conductance $(p=0.71)$ :

$g_{c}=g_{c, r e f} f_{1}(\theta) f_{2}(D)$

where $g_{c, r e f}$ is the canopy conductance at $D=1 \mathrm{kPa}$, and $f_{1}$ and $f_{2}$ are reduction functions of soil moisture ( $\theta$ ) and $D . f_{1}$ and $f_{2}$ are estimated from the observations inverting (3) and (4). Using the measured $F_{c}$ and $D$ we first estimate $f_{2}$ and $g_{c, \text { ref }}$ inverting (4) and using (5), when $g_{c}$ is not affected by soil moisture conditions, i.e. $\theta \leq 0.10 \mathrm{~m}^{3} \mathrm{~m}^{-3}$. Thus estimated, $g_{c, \text { ref }}$ was $0.0084 \mathrm{~m} \mathrm{~s}^{-1}$, similar to literature values (e.g., Larcher, 1995), and $f_{2}(D)$ was well-fitted as 1 - $0.6 D$ (Fig. 6c), common to a large number of species (Oren et al., 1999). Following, $f_{l}(\theta)$ was estimated using all the summer data of $E_{\mathrm{e}}, D, \theta$ and the estimated $f_{2}(D)$ through the inversion of (3) with (5) $\left(f_{1}(\theta)=5.798 \theta-0.201\right.$ for $0.08 \leq \theta<0.21$ and $f_{l}(\theta)=1$ for $\left.\theta \geq 0.21\right)$. Testing the skill of this simplified model to capture the variation in the 2003-2006 summer data, we used (4) with the modeled $g_{c}$ given by (5), and found the $F_{c}$ prediction in good agreement with observations ( $\mathrm{rmse}=2.07 \mu$ moles $\mathrm{CO}_{2} \mathrm{~m}^{-2} \mathrm{~s}^{-1}$ ), with the ratio of the total $N E E_{\mathrm{d}}$ predicted to observed of 0.98 .

The impact of the trend and variation of the number of Mistral days on $N E E_{\mathrm{d}}$ was then investigated using the simplified $F_{c}$ model, substituting the observed $D$ value in non-Mistral days with a $D=1.5 \mathrm{kPa}$, typical of Mistral days (Fig. 5). This substitution was made randomly among the non- 
Mistral days using a uniform distribution of 1000 combinations and varying the number of mistral days from the estimated minimum of 1 day to a maximum 20 days, or from $-85 \%$ to $+300 \%$ relative to the average of seven days during 2003-2006. If a Mistral day was randomly chosen beyond the number required for a particular run, it was assigned a $D$ selected at random from the 214 non-Mistral summer days available over the four years. Soil moisture was kept as it was in the randomly chosen day. The impact on summer $N E E_{\mathrm{d}}$ during the long-term decrease in Mistral frequency as well as in relations to the temperature-coupled inter-annual variation, are shown in Fig. 7.

\section{Discussion and conclusions}

Climate models predict changes in wind direction and velocity over many terrestrial biomes (Najac et al., 2009; McInnes et al., 2011; Najac et al., 2011; Rasmussen et al., 2011) with potential influences on water use efficiency and net ecosystems $\mathrm{C}$ exchange. Where such changes reduce the vapor pressure deficit during the vegetation active season, $W_{\mathrm{e}}$ may increase both due to increasing $c_{a}$ (Larcher, 1995; Keenan et al., 2013) and decreasing D (Meinzer, 1982; Baldocchi et al., 1987; Berbigier et al., 2001). In contrast, increases in $D$ may offset the positive effect of increasing $c_{a}$ on $W_{\mathrm{e}}$ and $N E E$. We use the effects of changing atmospheric conditions with wind direction in Sardinia as a case study, evaluating the potential effects of long-term trends in, and inter-annual variation of wind properties on $W_{\mathrm{e}}$ and NEE. Consistent with predictions of future decreases in Mistral in the western Mediterranean basin, the historical data in Sardinia shows a 75\% decrease in the frequency of Mistral days in Sardinia over the past five decades, from over a quarter of summer days to about a twentieth, compensated by a nearly equal $69 \%$ increase in the frequency of Sirocco days (H1).

Owing to travel over the sea, and contrasting $\mathbf{H 2}$, winds from both directions arrive at the Sardinian coast with a similarly low $D$ (Fig. 4a, and Fig. 5). This is because, although the Sirocco winds are warmer, their air holds more moisture than Mistral winds (Fig. 4b). $\Delta T_{\mathrm{a}}$ of air mass traveling 
over land reflects the integrated outcome of processes operating to reduce $T_{\mathrm{a}}$ (i.e. adiabatic cooling where air rises up a terrain), and others operating to increase it (i.e. outgoing sensible heat flux that is greater from the dry land surface than the sea surface, and, for quickly rising air, from net exchange of sensible heat with the warmer air of the entrainment zone). These effects on $T_{\mathrm{a}}$ were captured in both the observations (Fig. 4b) the simple thermal energy conservation using the time it takes a parcel of sea air to reach a point on the land (reflecting wind velocity, $u$, and distance traveled) and the sensible heat balance. The net effect was a decrease in $T_{a}$ during Mistral and an increase during Sirocco. On the other hand, the $Q_{\mathrm{a}}$ of the air decreased during both wind conditions as the air climbed from the cost to the closest meteorological station at a similar, $\sim 600 \mathrm{~m}$ a.s.l., but the decrease was more dramatic for Mistral air (Fig. 4c). This suggests a greater mixing for quickly rising air with the drier boundary layer air aloft as it travels on land up the elevation gradient, thus reducing $Q_{\mathrm{a}}$ more than in slow moving air. Despite a greater reduction of $Q_{\mathrm{a}}$ with travel on land, the opposite effects on $T_{\mathrm{a}}$ resulted in that $D$ increased less between the sea and Orroli during Mistral than other days (Fig. 5). Thus, consistent with popular awareness (and the simple formulation Eqn. 2), Mistral winds typically remain cool and maintain low $D$ as they transverse the island. In contrast, overwhelming the orographic cooling as they climb up, the warm, moist Sirocco winds warm up further and build humidity deficit (H3).

Based on the results above, the pasture-woodland ecosystem at Orroli is subjected to different summer $D$ conditions during Mistral than during Sirocco and localized weather. We assessed the effects of these different wind patterns on $\mathrm{CO}_{2}$ and water vapor fluxes using eddy-covariance measurements. In this ecosystem, $E_{\mathrm{e}}$ decreased progressively with $\theta$ during summer months, stabilizing by early July at $\sim 1.2 \mathrm{~mm} \mathrm{~d}^{-1}$, similar to estimated hydraulic redistribution (Domec et al., 2010), while the $\theta$ of the rooting zone reached a stable minimum value of $\sim 0.1 \mathrm{~m}^{3} \mathrm{~m}^{-3}$, except the unusual rain days (Fig. 3a). 
In most situations, reductions of $g_{c}$ compensate for increases of $D$ once the hydraulically tolerable maximum transpiration rate of the prevailing vegetation is reached (Oren et al., 1999; Oishi et al. 2010). However, greater stomatal resistance to $\mathrm{CO}_{2}$ uptake caused by higher atmospheric $D$, while not affecting $E_{\mathrm{e}}$ (Fig. 6a), reduced canopy photosynthesis and $N E E_{\mathrm{d}}$ (Fig. 6b; Baldocchi et al., 1987). Such wind-generated changes in $D$ caused a departure from a tradeoff between carbon and water, whereby increasing $\mathrm{C}$ sequestration must be at the cost of increasing $E_{\mathrm{e}}$ and decreasing water yield and availability to downstream users (Jackson et al., 2005). We demonstrated that, for the Orroli case study, the variation of wind direction can significantly alter $D$, and thus $g_{c}$, and consequently $\mathrm{CO}_{2}$ uptake and $W_{e}$ (Fig. 6c,d; H4). Scaling these effects based on the long-term decrease of Mistral frequency and inter-annual, temperature-related variation of the frequency, showed $>30 \%$ loss of summertime $N E E_{\mathrm{d}}$ historically, with an even greater effect of inter-annual variation (Fig. 7).

We note that increasing atmospheric $\mathrm{CO}_{2}$ concentrations might have, potentially, compensated for the effect on $N E E_{d}$ of increased summertime mean daytime $D$ with decreasing Mistral days. Indeed, over the period corresponding to the historical record (Fig. 2), atmospheric $\left[\mathrm{CO}_{2}\right]$ increased $\sim 25 \%$. However, assuming that $c_{a} / c_{i}$ (Eqn. 4) is insensitive to $c_{a}$ (Ellsworth et al., 2012), the positive effect on $N E E_{d}$ of increased $c_{a}$ would be similar, in relative term, to that increase of $c_{a}$, thus insufficient to nullify the effect of decreasing proportion of Mistral days. Accounting for the likely increase of summertime mean daytime $D$ with increasing proportion of Sirocco days, the partial compensation produced by increasing $c_{a}$ would be smaller still. We also note that the focus of this work on $N E E_{d}$ during the summer-dry period facilitated clearly isolating the effect of changing wind direction and associated atmospheric conditions. Clearly, in other geographical locations, and integrating over the entire year even in this Mediterranean ecosystem, stomatal conductance may be affected by additional factors (soil moisture, solar radiation, etc). Nevertheless, as long as changing wind direction affect $D$, the relative 
effect on stomatal conductance, and thus carbon uptake and water-use efficiency, will be conserved (Oren et al., 1999).

In Sardinia and other western Mediterranean ecosystems, where the air arriving at the shore is always of maritime characteristics, it is its $T_{\mathrm{a}}$ and velocity, largely affected by its origin, that determine how far inland low $D$ conditions will prevail. These Mesoscale processes affect the prevailing $D$, increasing or decreasing $W_{\mathrm{e}}$ without affecting the water cycle. In other settings, switching wind directions generate a range of $T_{\mathrm{a}}-R H$ combinations, in turn producing a range of $D$ (Sherwood and Fu, 2014). These wind properties produce spatiotemporal variation of atmospheric demand for water vapor, affecting $W_{\mathrm{e}}$ and $N E E_{\mathrm{d}}$, and must be considered when assessing ecosystem fluxes in regions where maritime and continental conditions switch, and where the future frequencies of these conditions are predicted to change with the climate.

\section{Acknowledgements}

This work was supported by the Regione Sardegna LR 7/2007 through grant \# CRP_79793. R.O. time was sponsored by the Swedish programs Trees and Crops for the Future (TC4F; SLU) and Nitrogen and Carbon in Forests (Nicaf; the research council Formas), and the Office of Science, US DOE. We

thank Anton Beljaars, Roni Avissar, Gabriel Katul, Torgny Näsholm, Lori Bennear and John Albertson for helpful discussions during the preparation of the manuscript, and ECMWF (European Centre for Medium-Range Weather Forecasts) data server for MACC II.

\section{References}

Baldocchi, D. D., 2003. Assessing the eddy covariance technique for evaluating carbon dioxide exchange rates of ecosystems: past, present and future. Global Change Biology, 9 (4), 479-492. 
Baldocchi, D.D., Verma, S.B., Anderson, D.E., 1987. Canopy photosynthesis and water-use efficiency in a deciduous forest. Journal of Applied Ecology, 24 (1), 251-260.

Berbigier, P., Bonnefond, J.-M., Mellmann, P., 2001. $\mathrm{CO}_{2}$ and water vapour fluxes for 2 years above Euroflux forest site. Agricultural and Forest Meteorology, 108, 183-197.

Burlando, M., 2009. The synoptic-scale surface wind climate regimes of the Mediterranean Sea according to the cluster analysis of ERA-40 wind fields. Theoretical and Applied Climatology, 96 (1-2), 69-83.

Conil, S., Hall, A., 2006. Local regimes of atmospheric variability: a case study of Southern California. Journal of Climate, 19, 4308-4325.

Cowan, I.R., 1978. Stomatal behaviour and environment. Advances in Botanical Research, 4, 117-228.

Detto, M., Montaldo, N., Albertson, J.D., Mancini, M., Katul, G., 2006. Soil moisture and vegetation controls on evapotranspiration in a heterogeneous Mediterranean ecosystem on Sardinia, Italy. Water Resources Research, 42 (8), W08419.

Detto, M., Katul, G., Mancini, M., Montaldo, N., Albertson, J. D., 2008. Surface heterogeneity and its signature in higher-order scalar similarity relationships, Agricultural and Forest Meteorology. $148,902-916$.

Doblas-Miranda, E., Martínez-Vilalta, J., Lloret, F., Álvarez, A., Ávila, A., Bonet, F. J., Brotons, L., Castro, J., et al., 2015. Reassessing global change research priorities in Mediterranean terrestrial ecosystems: how far have we come and where do we go from here? Global Ecology and Biogeography, 24, 25-43.

Domec, J.-C., King, J.S., Noormets, A., Treasure, E., Gavazzi, M.J., Sun, G., McNulty, S.G., 2010. Hydraulic redistribution of soil water by roots affects whole-stand evapotranspiration and net ecosystem carbon exchange. New Phytologist, 187, 171-183. 
Duursma, R.A., Kolari, P., Perämäki, M. et al., 2008. Predicting the decline in daily maximum transpiration rate of two pine stands during drought based on constant minimum leaf water potential and plant hydraulic conductance. Tree physiology, 28, 265-276.

Ellsworth, D.S. , Thomas, R., Crous, K.Y., Palmroth, S., Ward, E., Maier, C., Delucia, E., Oren, R., 2012. Elevated CO2 affects photosynthetic responses in canopy pine and subcanopy deciduous trees over 10 years: a synthesis from Duke FACE. Global Change Biology, 18, 223-242

Fosberger, M. A., Schroeder, M. J., 1966. Marine air penetration in central California, Journal of applied meteorology, 5, 573-589.

Furberg, M., Steynb, D.G., Baldic, M., 2002. The climatology of sea breezes on Sardinia. International Journal of Climatology, 22, 917-932.

Garratt, J.R., 1985. The inland boundary layer at low latitudes. Boundary-Layer Meteorology, 32, $307-$ 327.

Granger, R.J., Gray, D. M., 1989. Evaporation from natural nonsaturated surfaces. Journal of Hydrology, 11, 21-29.

Haxeltine, A., Prentice, I.C., 1996. BIOME3: An equilibrium terrestrial biosphere model based on ecophysiological constraints, resource availability, and competition among plant functional types. Global Biogeochemical Cycles, 10 (4), 693-709.

Huang, J., Lee, X., Patton, E.G., 2011. Entrainment and budgets of heat, water vapor, and carbon dioxide in a convective boundary layer driven by time-varying forcing, Journal of Geophysical Research, 116, D06308, doi:10.1029/2010JD014938

Hughes, M., Hall, A., 2010. Local and synoptic mechanisms causing Southern California's Santa Ana winds. Climate Dynamics, 34, 847-857.

Hurrell, J.W., 1995. Decadal trends in the North Atlantic Oscillation: regional temperatures and precipitation. Science, 269, 676-679. 
Jackson, R.B., Jobbagy, E.G., Avissar, R. et al., 2005. Trading water for carbon with biological carbon sequestration. Science, 310, 1944

Jarvis, P.G., 1976. The interpretation of the variations in leaf water potential and stomatal conductance found in canopies in the field. Philosophical Transactions of the Royal Society B, 273, 593-610.

Jones, H.G., 1998. Stomatal control of photosynthesis and transpiration. Journal of Experimental Botany, 49, 387-398.

Katul, G., Palmroth, S., Oren, R., 2009. Leaf stomatal responses to vapour pressure deficit under current and CO2-enriched atmosphere explained by the economics of gas exchange. Plant, Cell and Environment, 32, 968-979.

Keenan, T.F., Hollinger, D.Y., Bohrer, G., Dragoni, D., Munger, W.J., Schmid, H.P., Richardson, A.D., 2013. Increase in forest water-use efficiency as atmospheric carbon dioxide concentrations rise. Nature, 499 (7458), 324-327.

Kim, D., Oren, R., Oishi, A.C., Hsieh, C.I., Phillips, N., Novick, K.A., Stoy, P.C., 2013. Sensitivity of stand transpiration to wind velocity in a mixed broadleaved deciduous forest. Agricultural and Forest Meteorology, 187, 62-71.

Inness, A., Baier, F., Benedetti, A. et al., 2013. The MACC reanalysis: an 8 yr data set of atmospheric composition. Atmospheric Chemistry and Physics, 13 (8), 4073-4109.

Larcher, W., 1995. Physiological Plant Ecology, Springer, third edition, 506 pp.

Lionello, P., Sanna, A., 2005. Mediterranean wave climate variability and its links with NAO and Indian Monsoon. Climate Dynamics, 25 (6), 611-623,

McInnes, K.L., Erwin, T.A., Bathols, J.M., 2011. Global Climate Model projected changes in $10 \mathrm{~m}$ wind speed and direction due to anthropogenic climate change. Atmospheric Science Letters, 12, $325-333$. 
Meinzer, F.C., 1982. Models of steady-state and dynamic gas exchange responses to vapor pressure and light in Douglas fir (Pseudotsuga menziesii) saplings, Oecologia, 55, 403-408.

Moene, A.F., van Dam, J.C., 2014. Transport in the Atmosphere-Vegetation-Soil Continuum, Cambridge Univ. Press.

Montaldo, N., Albertson, J.D., Mancini, M., 2008. Vegetation dynamics and soil water balance in a water-limited Mediterranean ecosystem on Sardinia, Italy. Hydrology and Earth System Sciences, $12,1257-1271$.

Montaldo, N., Corona, R., Albertson, J.D., 2013. On the separate effects of soil and land cover on Mediterranean ecohydrology: two contrasting case studies in Sardinia, Italy. Water Resources Research, DOI: 10.1029/2012WR012171.

Najac, J., Boé, J., Terray, L., 2009. A multi-model ensemble approach for assessment of climate change impact on surface winds in France. Climate Dynamics, 32, 615-634, DOI 10.1007/s00382-008-0440-4.

Najac, J., Lac, C., Terray, L., 2011. Impact of climate change on surface winds in France using a statistical-dynamical downscaling method with mesoscale modelling. International Journal of Climatology, 31, 415-430.

Novick, K.A., Stoy, P.C., Katul, G.G., Ellsworth, D.S., Siqueira, M.B.S., Juang, J., Oren, R., 2004. Carbon dioxide and water vapor exchange in a warm temperate grassland. Oecologia, 138, 259274.

Oishi, A.C., Oren, R., Novick, K.A., Palmroth, S., Katul, G.G., 2010. Interannual invariability of forest evapotranspiration and its consequence to water flow downstream. Ecosystems 13, 421-436.

Oishi, A.C., Palmroth, S., Butnorc, J.R., Johnsend, K.H., Oren, R., 2013. Spatial and temporal variability of soil $\mathrm{CO}_{2}$ efflux in three proximate temperate forest ecosystems Agricultural and Forest Meteorology, 171-172, 256-269. 
Oren, R., Sperry, J.S., Katul, G.G., Pataki, D.E., Ewers, B.E., Phillips, N., Schafer, K.V.R., 1999. Survey and synthesis of intra- and interspecific variation in stomatal sensitivity to vapour pressure deficit. Plant Cell and Environment, 22, 1515-1526.

Oren, R., Hseih, C.I., Stoy, P., Albertson, J., McCarthy, H.R., Harrell, P., Katul, G.G., 2006. Estimating the uncertainty in annual net ecosystem carbon exchange: spatial variation in turbulent fluxes and sampling errors in eddy-covariance measurements. Global Change Biology, $12,883-896$.

Palutikof, J.P., Conte, M., Casimiro Mendes, J., Goodess, C.M., Espirito Santo, F., 1996. Climate and climate change. In: Brandt, C.J., Thornes, J.B., (eds) Mediterranean desertification and land use. John Wiley and Sons, London

Plant, R.S., Atkinson, B.W., 2002. Sea - breeze modification of the growth of a marine internal boundary layer. Boundary-Layer Meteorology, 104, 201-228.

Rasmussen, D.J., Holloway, T., Nemet, G.F., 2011. Opportunities and challenges in assessing climate change impacts on wind energy - a critical comparison of wind speed projections in California. Environmental Research Letters, 6, doi:10.1088/1748-9326/6/2/024008.

Raynor, G.S., Sethuraman, S., Brown, R.M., 1979. Formation and characteristics of coastal internal boundary layers during onshore flows. Boundary-Layer Meteorology, 16 (4), 487-514.

Schimel, D.S., House, J.I., Hibbard, K.A. et al., 2001. Recent patterns and mechanisms of carbon exchange by terrestrial ecosystems. Nature, 414 (6860), 169-172.

Schmid, H.P., 2002. Footprint modelling for vegetation atmosphere exchange studies: a review and perspective. Agricultural and Forest Meteorology, 113, 159-183.

Sherwood, S., Fu, Q., 2014. A Drier Future? Science, 343, 737

Stull, R.B., 1988. An Introduction to Boundary Layer Meteorology, Kluwer Academic Publishers, 666 pp. 
Stunder, M., Sethuraman, S., 1984. A comparative evaluation of the costal internal boundary - layer height equations. Boundary-Layer Meteorology, 32, 177-204.

Tagesson, T., Fensholt, R., Cropley, F., Guiro, I., Horion, S., Ehammer, A., Ardö, J., 2015. Dynamics in carbon exchange fluxes for a grazed semi-arid savanna ecosystem in West Africa. Agriculture, Ecosystems \& Environment, 205, 15-24.

Venkatram, A., 1977. A model of internal boundary-layer development. Boundary-Layer Meteorology, $11(4), 419-437$.

Vinelli, M., 1926. Water conservation in Sardinia. Geographical Review, 16 (3), 395-402.

Wetzel, P.J., Chang, J.T., 1987. Concerning the relationship between evapotranspiration and soil moisture. Journal of Climate and Applied Meteorology, 26, 18-27. 


\section{Figure legends}

Figure 1. Map of Sardinia in the western Mediterranean basin with meteorological station locations (blue circles), the Orroli micrometeorological station location (green circle), Mistral and Sirocco directions (blue and red arrows respectively) and the grid of the MACC II re-analysis outputs (cross; the cells of the grid used in determining Mistral and Sirocco conditions are shown as diamonds).

Figure 2. a) Days with Mistral conditions $\left(u>4.75 \mathrm{~m} \mathrm{~s}^{-1}\right.$, corresponding to $>7 \mathrm{~m} \mathrm{~s}^{-1}$ over the sea) as percent of summer days based on historical record from Alghero meteorological station decreased over five-decade. b) Days with Sirocco conditions $\left(u>5.3 \mathrm{~m} \mathrm{~s}^{-1}\right.$, corresponding to $>5$ $\mathrm{m} \mathrm{s}^{-1}$ over the sea) as percent of summer days based on historical record from Elmas meteorological station decreased over the same period.

Figure 3. Soil and atmospheric conditions during summer drought period at the flux site. (a) Soil moisture $(\theta)$ time series. The histogram of $\theta$ is shown as inset, highlighting the mode of 0.08-0.1. (b) Atmospheric vapor pressure deficit $(D)$ is increasing as summer drought begins, and decreases as the drought eases. During the drought period $D$ was highly variable at the site (and other Sardinian weather stations), with $D$ of Mistral days typically low and of Sirocco days typically high. Symbol shapes distinguish among four years (2003: square, 2004: triangle up, 2005: triangle down, 2006: circle). Vertical dotted lines indicate the summer dry period considered in later analyses.

Figure 4. Properties of air embarking on Sardinia and their effects on vapour pressure deficit $(D)$. (a) Banners representing $T_{\mathrm{a}}$ (color) and $D$ (width) on one typical Mistral day and one typical Sirocco day are shown above a topographic representation of the island, interpolated between five weather stations along a northwest-southeast transect [beginning from the northwest end of the island: Alghero, Macomer, Orroli (marked with asterisk), Perdasdefogu, and Capo San Lorenzo]. 
(b) The air of an average Mistral day arriving at the northwestern coast has a lower temperature $\left(T_{\mathrm{a}}\right)$ and absolute humidity $\left(Q_{\mathrm{a}}\right)$ than that of a Sirocco day arriving at the southeastern coast (In each box, red line indicates the means and black line the median, the box and whiskers represent quartiles, and outliers are depicted individually; different letters indicate results of two-tailed ttest at $P=0.05$ ). (c) Moving from the coast up the mountain to the position of the next meteorological station, $T_{\mathrm{a}}$ decreased during Mistral days and increased during Sirocco days, while $Q_{\mathrm{a}}$ of air embarking on the island decreased with travel up elevation more in Mistral than Sirocco days.

Figure 5. Increases of vapor pressure deficit $(D)$ in air masses moving from the Mediterranean near the coast to the flux site in Orroli. Near the coast, days classified as having no dominating wind direction and lower wind velocity than Mistral days showed slightly higher $D$ than either Mistral or Sirocco days. However, reaching Orroli, $D$ during high wind velocity Mistral days increased less than during other days, in which $D$ was $~ 45 \%$ higher. In each box, dotted line indicates the means and solid line the median, the box and whiskers represent quartiles, and outliers are depicted individually; different letters indicate results of two-tailed t-test at $P=0.05$.

Figure 6. Ecosystem fluxes as affected by vapour pressure deficit $(D)$. (a) Ecosystem evaporation $\left(E_{\mathrm{e}}\right)$, a proxy of canopy transpiration during the summer dry period was independent of $D$, while (b) daytime net ecosystem carbon exchange $\left(N E E_{\mathrm{d}}\right)$ decreased with $D$ as a result of (c) decreasing $g_{\mathrm{c}}$, as did ecosystem water-use efficiency $\left(W_{\mathrm{e}}=N E E_{\mathrm{d}} / E_{\mathrm{e}}\right) .(\mathrm{d})$ Because Mistral days are in general lower $D$ days than days of localized weather, and Sirocco days are often higher $D$ days than normal, $g_{\mathrm{c}}$ and $W_{\mathrm{e}}$ tended to decreases moving from Mistral to normal to Sirocco days (different letters indicate dissimilarity at $P<0.05$ based on ANOVA-based Dunn's mean-separation). Statistics shown in the box and whiskers diagram are as in Fig. $3 b$. 
Figure 7. Simulated changes of $N E E_{\mathrm{d}}$ (see text) with changes of the number of summer Mistral days relative to the average during the flux measurement period of 2003-2006 (dashed vertical line). The reduction in Mistral days observed over five-decades is delineated in red vertical lines, and the average inter-annual amplitude in blue, both taken from Fig. 1; in each estimation box, the statistics of 1000 runs are shown: red line indicates the means and black line the median, the box and whiskers represent quartiles, and outliers are depicted individually. 


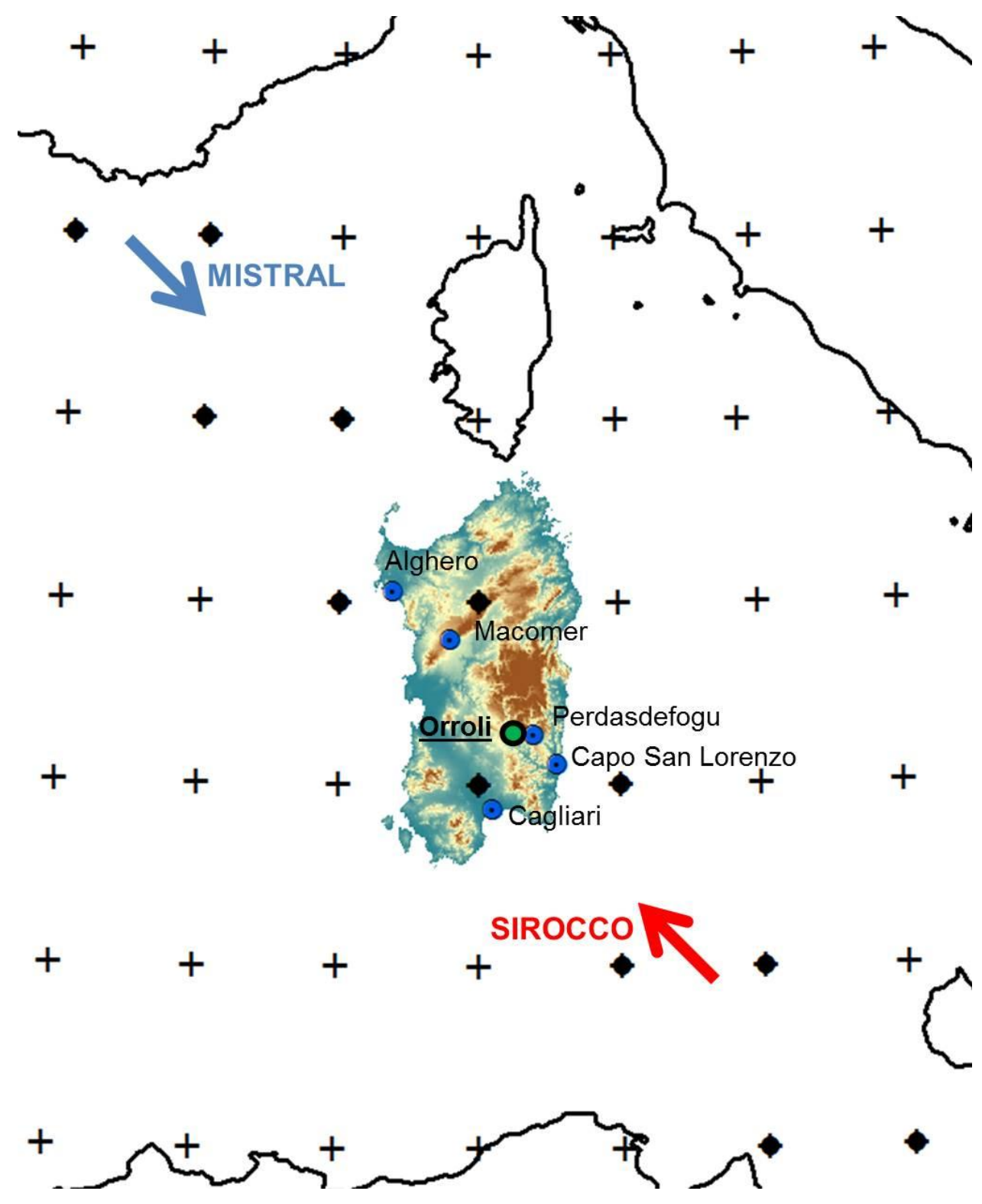

Fig.1. 

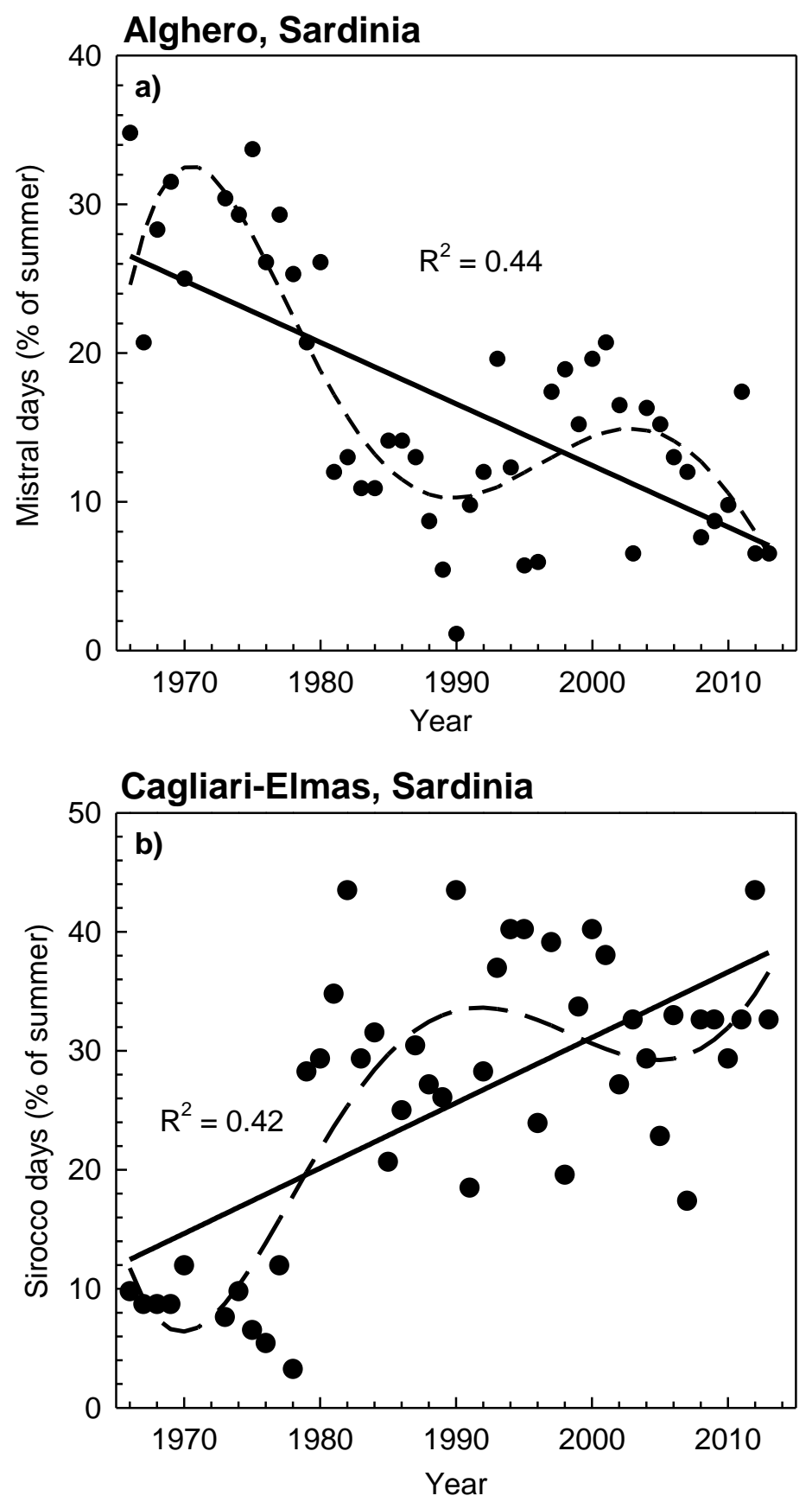

Fig.2. 

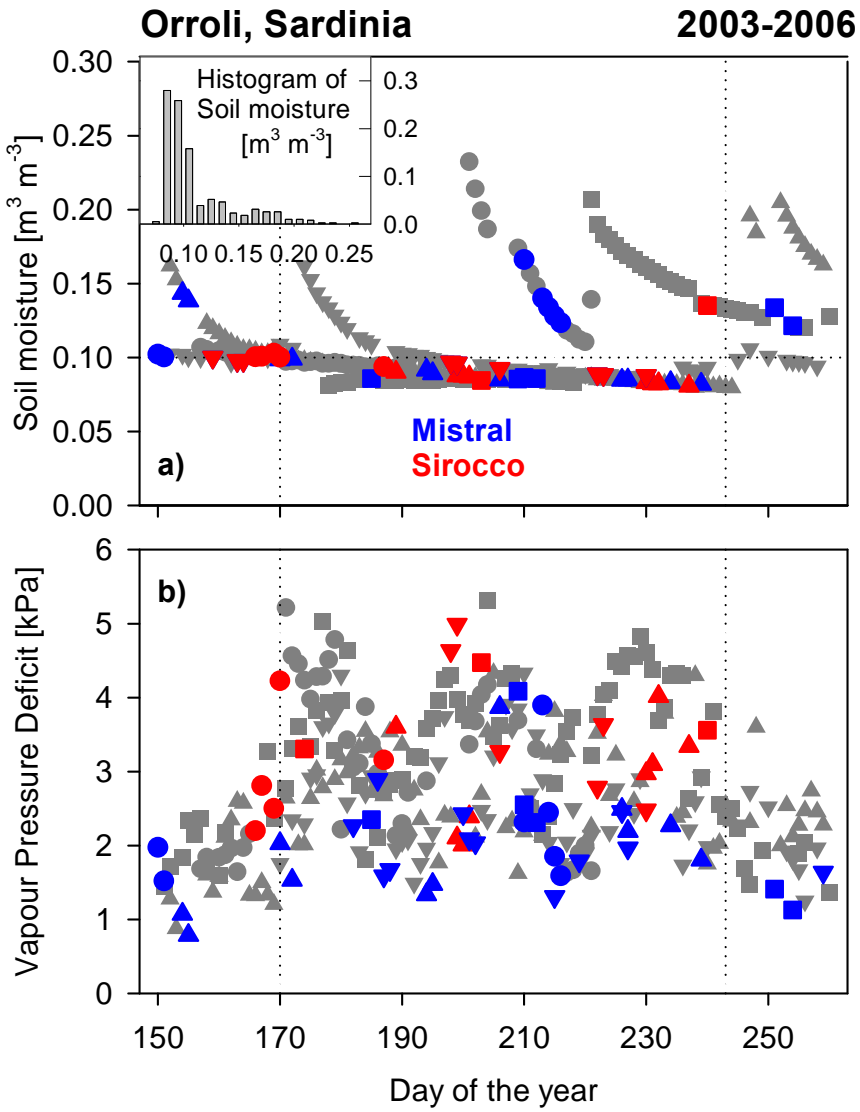

Fig. 3 

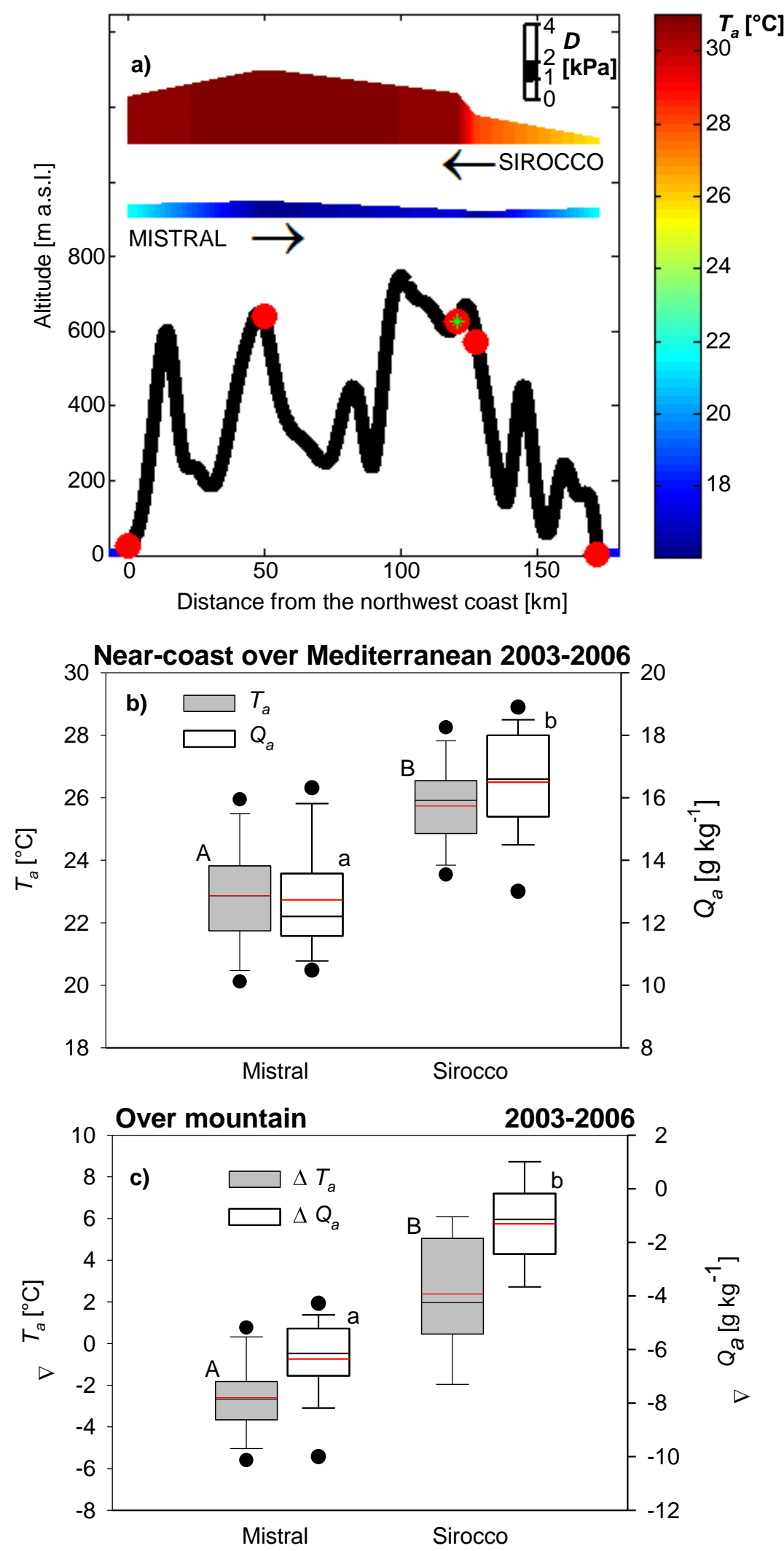

Figure 4. 


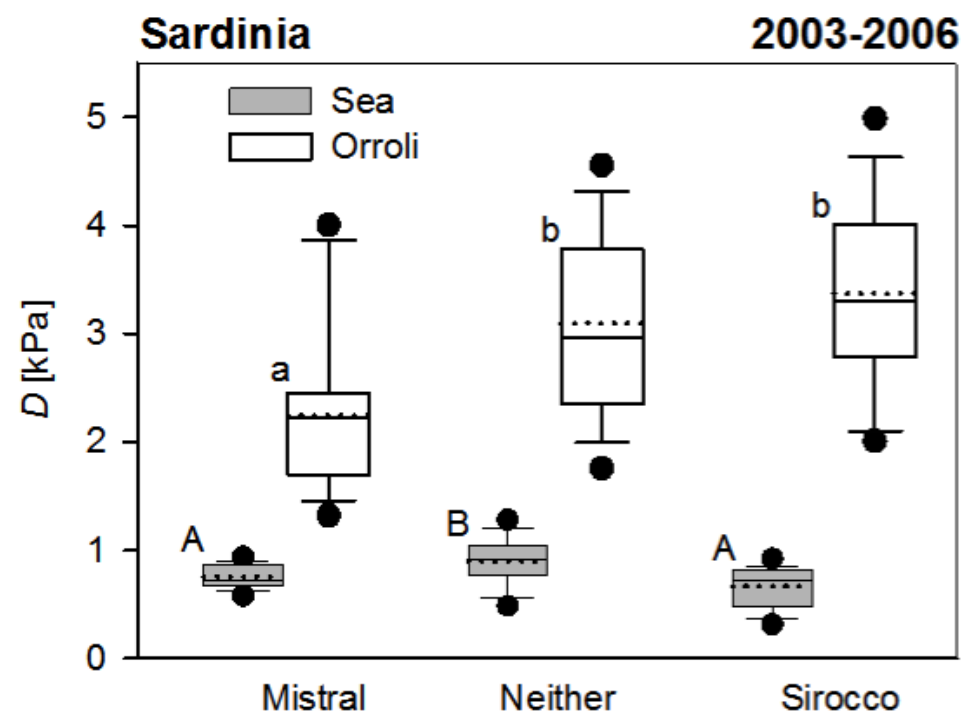

Figure 5. 

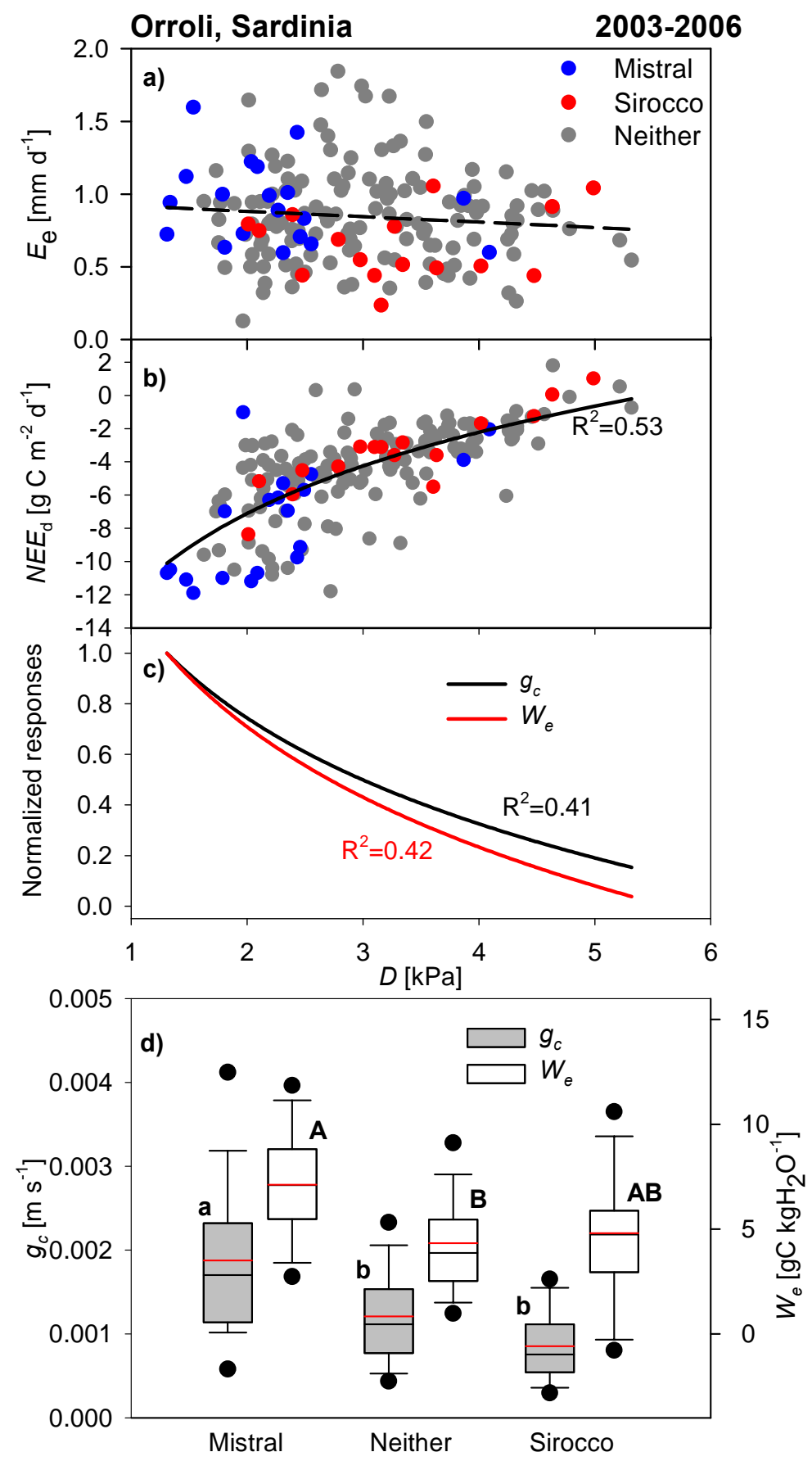

Figure 6. 


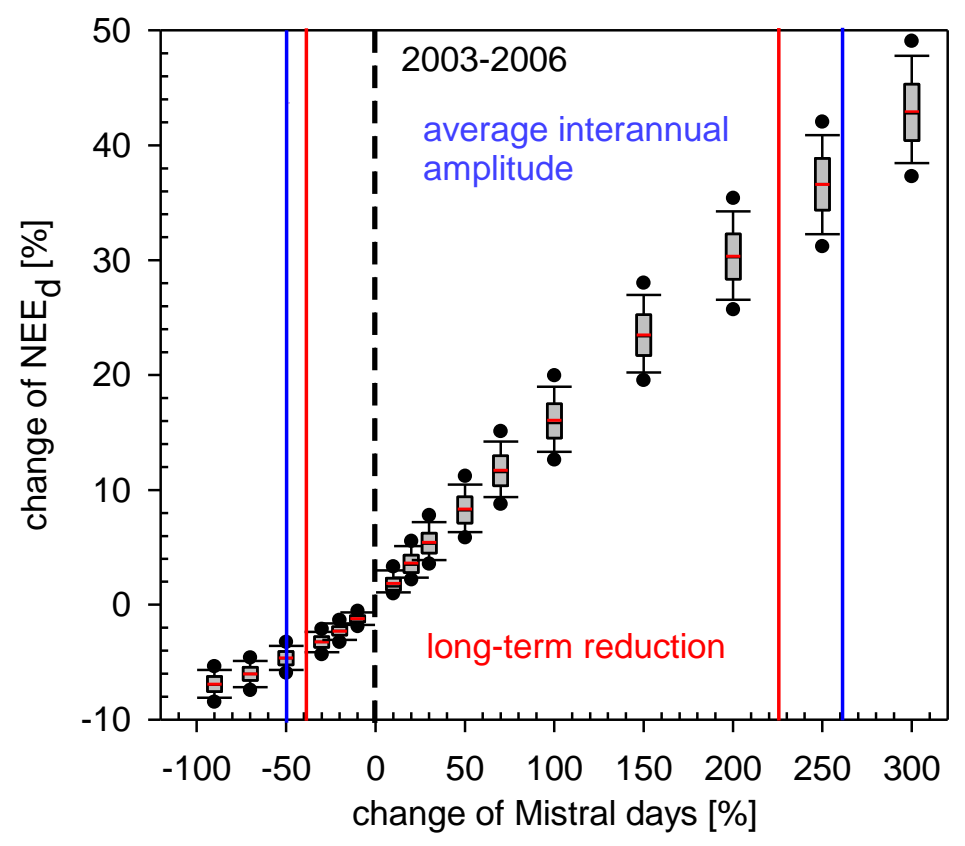

Figure 7. 